\title{
The study of multivariance in realization of the plum graft and rootstock combinations adaptivity systems to the changing conditions of environment in the Krasnodar region with the use of digital technologies
}

\author{
Irina Dragavtseva ${ }^{1 *}$, Anna Kuznetsova ${ }^{1}$, Igor Savin ${ }^{2,3}$, and Anna Klyukina ${ }^{1}$ \\ ${ }^{1}$ Federal State Budget Scientific Institution «North Caucasian Federal Scientific Center of Horticulture, \\ Viticulture, Wine-making», 39 str. 40 Let Pobedy, Krasnodar, 350901, Russia \\ ${ }^{2}$ Peoples' Friendship University of Russia, 6 str. Miklukho-Maklaya, Moscow, 115093, Russia \\ ${ }^{3}$ V.V. Dokuchaev Soil Science Institute, 7 Pyzhevsky lane, Moscow, 119017, Russia
}

\begin{abstract}
The study of rootstocks group, providing the average vigor of growth for the grafted fruit plants, discovered their significant influence on the frost hardiness of the "graft-rootstock" system. The adaptivity of the plum varieties in the different graft and rootstock combinations was studied according to the "frost hardiness" criterion in the stages of the winter and spring development of the flower buds. The computer maps of the plum efficient allocation were created on the studied rootstocks, permitting to lay down the plantings with the lesser risks in the terms of climate fluctuation. It was established, that in the south of Russia the climatic conditions to cultivate Stanley variety on PK SK 1 rootstock, as compared with the rootstock of cherry plum seedling, mostly often used in industrial plantings of plum are mostly favorable. The conducted research contributes to isolation and allocation of the most adaptive graft and rootstock combinations based on their frost hardiness and, consequently, regularity of fruit-bearing and yielding capacity.
\end{abstract}

\section{Introduction}

To date, it is proved that a rootstock has impact on the vigor of plant growth, its resistance to the stress factors of biotic and abiotic nature [1-3]. But it is known very little about the manifestation of properties of the graft and rootstock combinations on the new rootstocks in the various conditions of environment and at the different stages of ontogenesis, although this knowledge is necessary to expand the opportunities of regulating the vital functions of the fruit cultures and their varieties [4-8].

In the existing literature, the prominence is given to two alternative hypotheses regarding the degree of graft and rootstock integration in the signs of a grafted plant operating as a holistic organism. The first of these hypotheses is based on the notion about the deep integration of the graft and rootstock properties in the holistic organism of the grafted tree.

\footnotetext{
* Corresponding author: $\underline{I \mathrm{~d} @ \text { list.ru }}$
} 
According to the second hypothesis, the natural interaction of the grafting components has a predominantly trophic nature, therefore the effect of the rootstock on grafting is similar to the influence of soil fertility factors on a true-rooted tree. However, at the same time, grafting seeks to maintain actively its genetically determined reaction rate. That is, the rootstock is similar to the complex of the environment factors for grafting, and consequently the interaction of grafting and rootstocks is similar to the mutual influence of the "genotype environment", for the mathematical description of which a lot of formulations has been developed by biometric genetics.

The paper by A. P. Kuznetsova and S. N. Shcheglov [9] brings to light the dynamics of variability in the fruit trees graft and rootstock combination depending on the changing environment conditions. The method of mathematical modeling proved the influence of the rootstock on homeostaticity of the fruit plants production process at the different stages of plant development. Thus, by now, the scientists have formed the opinion that the "combined individual" appearing as a result of grafting complies with its own new regularities, thanks to the exchange processes between the rootstock and graft.

The normal adaptation of fruit trees to the terms and conditions of environment and agricultural technologies is ensured by the correct selection of the grafts and rootstocks, the possibility of varying combination effects, which become a decisive factor in achieving optimal productivity of the longstanding fruit cultures. The paper is concerned with the development of a new technology for managing the yielding capacity of the fruit cultures, as exemplified by the plum graft and rootstock combination.

\section{Materials and methods}

The objects of research - Kabardinskaya Ranniaya and Stanley plum varieties at the Limited Liability Company "Plodovod" and Experimental production farm "Tsentralnoye" on the rootstocks: - seedlings of cherry plum Prunus Cerasifera (control); - PK SK 1 - selected by the Federal State Budgetary Scientific Institution «North Caucasian Federal Scientific Center of Horticulture, Viticulture, Wine-making» and Stavropol Experimental station of plantbreeding - (P. pumila L. x P. cerasifera Ehrh.) X P. cerasifera Ehrh.). The garden was planted in 2007.

The research base: the years-long meteorological data of the various gardening zones of Krasnodar region (1985-2020) - Prikuban zone of horticultural activity (meteorological station of Krasnodar), Western piedmont zone (meteorological station of Goryachiy Kliuch), Steppe zone (meteorological station of Tikhoretsk) for two periods (1985-2000 and 20012020), taking into account climate fluctuations. Their interpolation into the geographic points of the region at a scale of $250 \mathrm{~m}$ for the leveled out areas and $50 \mathrm{~m}$ in the rugged relief.

When evaluating the winter hardiness and adaptability of the graft and rootstock combinations, the generally accepted methods were used [10]. The regularities of manifestation of the fruit plant genotypes in phenotype, when climate changes, were determined by the method of V.A. Dragavtseva et al. [11], a digital spatial analysis of the plum graft and rootstock combination rational placement in Krasnodar region, depending on the winter and spring period conditions, was carried out according to the method of I.Yu. Savin et al. [12].

\section{Results and discussion}

When studying the yielding capacity of fruit cultures, the particular species, varieties of plants and their graft-rootstock combinations, as well as specific habitats, provided, to a certain extent, by the factors of natural resources that limit the yield, serve as the permanent objects. The variables are the amount of resources, the critical levels of which depend on the 
hereditary characteristics of the plants under study, in particular, the graft-rootstock combinations of the plum. Therefore, the study of the influence of the rootstock and scion on frost resistance and, consequently, the yielding capacity in the whole organism of a fruit tree is important both in theoretical and practical terms.

Considering that the increase in the area of the plum growing in the south of Russia is limited by the temperature limits for particular phases of development, the critical minimum temperatures of the winter and spring period of various combinations of scion and rootstock have been established (Table 1).

Table 1. The critical minimum temperatures of air for the flower buds of Stanley and Kabardinskaya Ranniaya plum varieties grafted by cherry plum and PK SK 1 at the stages of winter and spring period (averaged reading for the south of Russia).

\begin{tabular}{|c|c|c|c|c|c|}
\hline \multicolumn{2}{|c|}{$\begin{array}{c}\text { Stages of winter and } \\
\text { spring period }\end{array}$} & \multicolumn{2}{|c|}{ Cherry plum graft } & \multicolumn{2}{c|}{ PK SK 1 graft } \\
\cline { 3 - 6 } \multicolumn{2}{|c|}{$\begin{array}{c}\text { Biological } \\
\text { rest }\end{array}$} & Stanley & $\begin{array}{c}\text { Kabardinskay } \\
\text { a Ranniaya }\end{array}$ & Stanley & $\begin{array}{c}\text { Kabardinskay } \\
\text { a Ranniaya }\end{array}$ \\
\cline { 2 - 6 } & Abs. Min & $<-32$ & $<-26$ & $<-34$ & $<-28$ \\
\cline { 2 - 6 } & Decades & February I & February I & February & February I \\
& III & $\begin{array}{c}\text { January I, II, } \\
\text { III }\end{array}$ & $\begin{array}{c}\text { January I, } \\
\text { II, II }\end{array}$ & $\begin{array}{c}\text { January I, II, } \\
\text { III }\end{array}$ \\
\cline { 2 - 6 } & Abs. Min & $<-28$ & $<-24$ & $<-30$ & $<-25$ \\
\hline \multirow{4}{*}{$\begin{array}{c}\text { Exogenous } \\
\text { dormancy }\end{array}$} & Decades & February II, & February II, & February & February II, \\
& IfI, III & III \\
\cline { 2 - 6 } & Abs. Min & $<-28$ & $<-22$ & $<-26$ & $<-20$ \\
\hline $\begin{array}{c}\text { Swelling of } \\
\text { flower buds }\end{array}$ & Decades & March I & March I & March I & March I \\
\cline { 2 - 6 } & Abs. Min & $<-18$ & $<-15$ & $<-20$ & $<-15$ \\
\cline { 2 - 6 } & Decades & March II & March II & March II & March II \\
\cline { 2 - 6 } & Abs. Min & $<-16$ & $<-12$ & $<-17$ & $<-12$ \\
\hline \multirow{2}{*}{$\begin{array}{c}\text { Bud } \\
\text { dehisced, } \\
\text { sepals are } \\
\text { visible }\end{array}$} & Decades & March III & March III & March III & March III \\
\cline { 2 - 6 } & Abs. Min & $<-13$ & $<-10$ & $<-13$ & $<-10$ \\
\cline { 2 - 6 } & Decades & April I & April I & April I & April I \\
\cline { 2 - 6 } & Abs. Min & $<-10$ & $<-8$ & $<-10$ & $<-8$ \\
\hline $\begin{array}{c}\text { Start of } \\
\text { flowering }\end{array}$ & Decades & April I & April I & April I & April I \\
\cline { 2 - 6 } & Abs. Min & $<-2$ & $<-1$ & $<-3$ & $<-2$ \\
\hline
\end{tabular}

It follows from those that the PK SK 1 stock increases the frost resistance of grafted trees, as compared with the other studied ones. It is also seen that Stanley variety, taken as a scion, enhances also the frost resistance of trees in comparison with Kabardinskaya Ranniaya scion.

The probability of the temperature stresses manifestation in the winter and spring period, which reduces the yield of the plum graft-rootstock combinations under study for two periods of years, was calculated (Table 2).

All this proves that the systems of graft and rootstock combination adaptability feature multivariance of their implementation in terms of climate change. The results obtained open up the possibility of creating a new technology for the management of the fruit plants production process under the climate fluctuations [13-17]. 
Table 2. The probability (\%) of manifestation of the winter and spring period temperature stresses, reducing the yield (economically unjustified) of the plum graft and rootstock combinations by 90-100 percent in the different zones of horticultural activities of Krasnodar region

\begin{tabular}{|l|c|c|}
\hline \multirow{2}{*}{$\begin{array}{l}\text { Description of graft and rootstock } \\
\text { combination }\end{array}$} & \multicolumn{2}{|c|}{ Periods of years } \\
\cline { 2 - 3 } Meteorological station of Krasnodar (Prikuban zone of horticultural activity) \\
\hline \multicolumn{1}{|c|}{} & 6,6 & 15,8 \\
\hline Stanley/cherry plum & 6,6 & 10,5 \\
\hline Stanley/ PK SK 1 & 13,3 & 21,0 \\
\hline $\begin{array}{l}\text { Kabardinskaya Ranniaya/cherry } \\
\text { plum }\end{array}$ & 6,6 & 10,5 \\
\hline Kabardinskaya Ranniaya/PK SK 1 & 0 & 15,8 \\
\hline \multicolumn{2}{|c|}{ Meteorological station of Goryachiy Kliuch (Piedmont zone of horticultural activity) } \\
\hline Stanley/cherry plum & 0 & 10,5 \\
\hline Stanley/ PK SK 1 & 6,6 & 57,0 \\
\hline $\begin{array}{l}\text { Kabardinskaya Ranniaya/cherry } \\
\text { plum }\end{array}$ & 0 & 26,3 \\
\hline Kabardinskaya Ranniaya/PK SK 1 & 6,6 & 31,5 \\
\hline \multicolumn{2}{|c|}{ Meteorological station of Tikhoretsk (Steppe zone of horticultural activity) } \\
\hline Stanley/cherry plum & 0 & 23,0 \\
\hline Stanley/ PK SK 1 & 13,3 & 37,9 \\
\hline $\begin{array}{l}\text { Kabardinskaya Ranniaya/cherry } \\
\text { plum }\end{array}$ & 13,3 & 26,3 \\
\hline Kabardinskaya Ranniaya/PK SK 1 & & \\
\hline
\end{tabular}

To reduce the risk of growing the plum graft and rootstock combination in the winter and spring period in Krasnodar region, a spatial-temporal analysis of the minimum air temperatures onset for 1986-2017 was carried out in the stages of winter and spring development for Stanley variety on the cherry plum and PK SK 1 rootstocks. Through the use of geoinformation technologies [15], the relevant maps of land suitability were constructed, and the trend of the prospective selection of lands to cultivate the plum graft and rootstock combination was shown, taking into account the fluctuations of climate of the winter and spring period for the last 10 years (Fig. 1).

a)

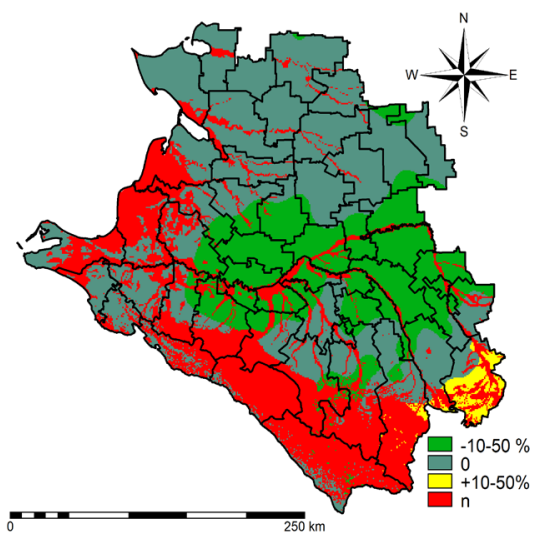

b)

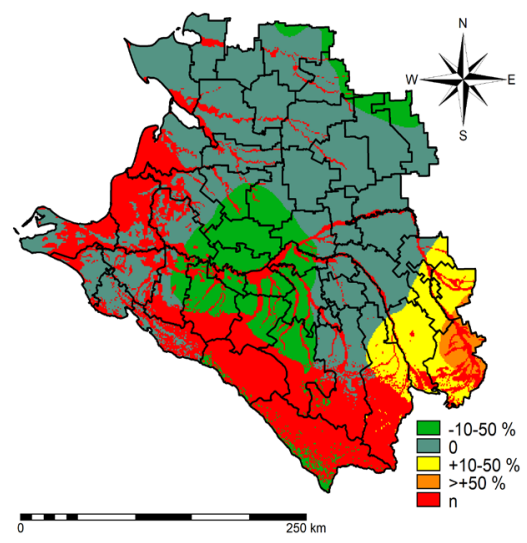

Fig. 1. The longstanding trend of the lands suitability for cultivation of Stanley plum under the winter and spring terms on the cherry plum (a) and PK SK 1 (b) rootstocks in Krasnodar region Note: The values with minus is a region, where situation is better (the risks reduce), the values with plus means the territories, where the risks grow (the suitability becomes worse). 
The computer maps of land suitability for Stanley graft and rootstock combination have been developed. The resulting maps were further divided into classes in accordance with the probability of crop failure: probability $0,<10 \%, 10-25 \%, 25-50 \%, 50-75 \%, 75-90 \%,>90 \%$ (Fig. 2).

a)

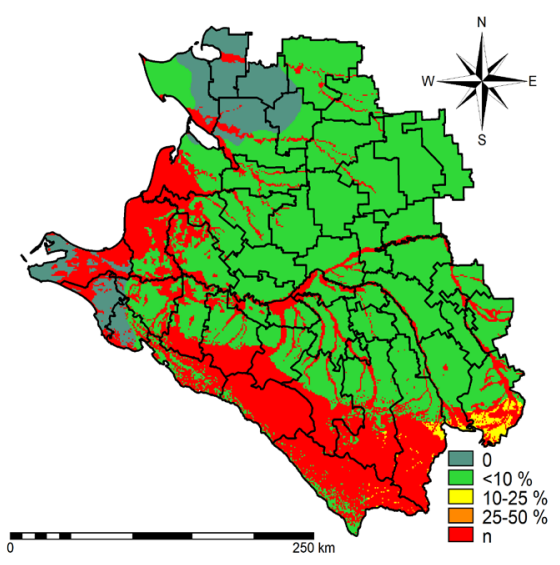

b)

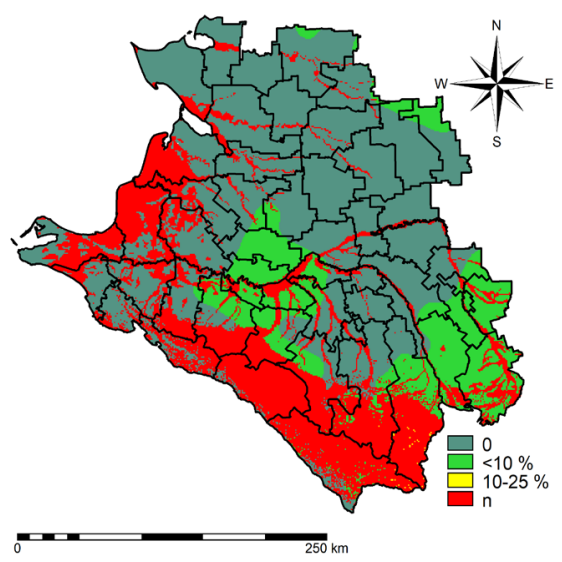

Fig. 2. The suitability of lands (the percentage of reduction in yields probability) to cultivate Stanley plum under the winter and spring terms on the cherry plum (a) and PK SK 1 (b) rootstocks in Krasnodar region

The areas of lands varying in suitability classes, calculated for example by Stanley variety on PK SK 1 and cherry plum, are given in Table 3.

Table 3. The longstanding trend of the lands suitability in the observable climatic fluctuations

\begin{tabular}{|l|c|c|c|c|c|c|c|c|c|c|}
\hline \multirow{2}{*}{$\begin{array}{l}\text { Graft and } \\
\text { rootstock } \\
\text { combinations }\end{array}$} & \multicolumn{9}{|c|}{ Classes of changing trend of suitability } \\
\cline { 2 - 12 } & \multicolumn{2}{|c|}{$-10-50 \%$} & \multicolumn{2}{|c|}{0} & \multicolumn{2}{|c|}{$+10-50 \%$} & \multicolumn{2}{|c|}{$>+50 \%$} & \multicolumn{2}{|c|}{$\mathrm{n}$} \\
\cline { 2 - 11 } & $\%$ & ths.ha & $\%$ & ths.ha & $\%$ & ths.ha & $\%$ & ths.ha & $\%$ & ths.ha \\
\hline $\begin{array}{l}\text { Stanley/ PK } \\
\text { SK 1 }\end{array}$ & 14.9 & 1235.9 & 46.3 & 3830.0 & 6.6 & 549.1 & 1.2 & 103.0 & 30.9 & 2564.9 \\
\hline $\begin{array}{l}\text { Stanley/ } \\
\text { cherry plum }\end{array}$ & 23.1 & 1914.7 & 44.4 & 3685.5 & 1.5 & 127.6 & 0 & 0 & 30.9 & 2564.9 \\
\hline
\end{tabular}

\section{Conclusion}

It was found that PK SK 1 rootstock increases the frost resistance of grafted plants as compared with cherry plum.

The significant positive effect of the PK SK 1 rootstock on the frost resistance of Stanley and Kabardinskaya Ranniaya plum trees at the different stages of the winter and spring period was revealed.

In general, the winter and spring conditions in Krasnodar region are more favorable for the cultivation of Stanley plums on the PK SK 1 rootstock.

The multivariance of the systems of graft and rootstock combination adaptability to an unfavorable winter and spring period in the new climatic conditions has been revealed, which will be used to create a new technology for managing yielding capacity of fruit plants. The integral computer maps have been developed for the optimal placement of zoned plum varieties in Krasnodar region, in the context of its 44 districts, which allow, taking into account the climate fluctuations, more reasonably, with minimal risks from unfavorable 
conditions of the winter and spring period, to establish the new plum plantations and are elements of resource-saving technology to grow plums.

Acknowledgments. The research was carried out with the financial support of the Russian Foundation for Basic Research and administration of Krasnodar Territory within the framework of scientific project nr. 19-44-230023 p_a

\section{References}

1. A. Albacete, C. Martínez-Andújar, A. Martínez-Pérez, A.J. Thompson, I.C. Dodd, F. Pérez-Alfocea, J. Exp. Bot., 66(8), 2211-2226 (2015) https://doi.org/10.1093/jxb/erv027

2. E. Marguerit, O. Brendel, E. Lebon, C. Van Leeuwen, N. Ollat, New Phytol., 194, 416429 (2012) https://doi.org/10.1111/j.1469-8137.2012.04059.x

3. M. Yahmed, M. Ghrab, B. Mimoun, Fruits, 71, 185-193 (2016) https://doi.org/10.1051/fruits/2016003

4. G. Bujdosó, K. Hrotko, Hort. Sci., 32, 129-137 (2018) https://doi.org/10.17221/3779HORTSCI

5. D.K. Jayswal, N. Lal, Agriallis, 2(11), 10-16 https://www.researchgate.net/publication/346097430

6. A. Dekena, P. K. Kahu, V. Laugale, I. Alsina, Proceedings of the Latvian Academy of Sciences. Section B. Natural, Exact, and Applied Sciences, 71(3), 233-236 (2017) http://doi.org/10.1515/prolas-2017-0039

7. A. Indreiaş, V.A. Opriţa, G. Lamureanu, I. Caplan, Acta Hortic., 968, 147-152 (2012) https://doi.org/10.17660/ActaHortic.2012.968.20

8. A. Indreias, Acta Hortic., 903, 507-511 https://doi.org/10.17660/ActaHortic.2011.903.70

9. A. Kuznetsova, I. Dragavtseva, A. Drygina, A. Klyukina, S. Shcheglov, E3S Web Conf., 254, 02022 (2021) https://doi.org/10.1051/e3sconf/202125402022

10. N. Nenko, I. Ilina, N. Zaporozhets, G. Kiseleva, T. Skhalyakho, BIO Web Conf., 25, 02015 (2020) https://doi.org/10.1051/bioconf/20202502015

11. V.A. Dragavtsev, I.A. Dragavtseva, I.L. Efimova, A.P. Kuznetsova, A.S. Morenets, Agric. Biol., 1, 151-156 (2018) https://doi.org/10.15389/agrobiology.2018.1.151eng

12. I. Savin, A. Klyukina, I. Dragavtseva, International Multidisciplinary Scientific GeoConference: $\quad$ SGEM, 20(2.2), 157-163 http://doi.org/10.5593/sgem2020/2.2/s10.019

13. Y. Ding, Z. Li, S. Peng. Int. J. Appl. Earth Obs. Geoinf., 92, 102179 (2020) https://doi.org/10.1016/j.jag.2020.102179

14. E. Luedeling, E.H. Girvetz, M.A. Semenov, P.H. Brown, PLoS One, 6(5), e20155 (2011) https://doi.org/10.1371/journal.pone.0020155

15. E. Fadón, S. Herrera, B.I. Guerrero, M.E. Guerra, J. Rodrigo, Agronomy, 10(3), 409 (2020) https://doi.org/10.3390/agronomy10030409

16. E. Balogh, J. Halasz, A. Solteszt, Z. Erös-Honti, Á. Gutermuth, L. Szalay, M. Höhn, A. Vágújfalvi, G. Galiba, A. Hegedus, Front. Plant. Sci., 10, 402 (2019) https://doi.org/10.3389/fpls.2019.00402

17. K.M. Becklin, J.T. Anderson, L.M. Gerhart, S.M. Wadgymar, C.A. Wessinger, J.K. Ward, Plant Physiol., 172, 635-649 (2016) https://doi.org/10.1104/pp.16.00793 